\title{
Developmental Assets, Self-Control and Internet Gaming Disorder in Adolescence: Testing a Moderated Mediation Model in a Longitudinal Study
}

\author{
Guo-Xing Xiang ${ }^{1}$, Xiong Gan ${ }^{1 *}$, Xin Jin $^{2}$, Yan-Hong Zhang ${ }^{1}$ and Cong-Shu Zhu ${ }^{1}$ \\ ${ }^{1}$ Department of Psychology, College of Education and Sports Sciences, Yangtze University, Jingzhou, China, ${ }^{2}$ Yangtze \\ University College of Technology and Engineering, Jingzhou, China
}

From the perspective of positive youth development, developmental assets and self-control play critical roles in promoting adolescent development. However, their effects have not been evaluated in the current issue, internet gaming disorder (IGD). IGD is gradually becoming an important social problem among worldwide youth and

OPEN ACCESS

Edited by:

Yanhui Liao,

Zhejiang University School of

Medicine, China

Reviewed by:

Denisse Manrique-Millones,

University of Lima, Peru

Jian-Bin Li,

The Education University of Hong

Kong, Hong Kong SAR, China

*Correspondence:

Xiong Gan

307180052@qq.com

Specialty section:

This article was submitted to

Public Mental Health,

a section of the journal

Frontiers in Public Health

Received: 03 November 2021

Accepted: 04 January 2022

Published: 04 February 2022

Citation:

Xiang G-X, Gan X, Jin X, Zhang Y-H and Zhu C-S (2022) Developmental

Assets, Self-Control and Internet

Gaming Disorder in Adolescence:

Testing a Moderated Mediation Model

in a Longitudinal Study.

Front. Public Health 10:808264.

doi: 10.3389/fpubh.2022.808264 has been included in the eleventh International Classification of Diseases (ICD-11). Therefore, the present study was determined to investigate the relationship between developmental assets, self-control, and IGD. A two-wave longitudinal study, with each wave spanning half a year apart, was conducted in a sample of 1023 adolescents (aging from 11 to $15,49.36 \%$ boys) during the COVID-19 pandemic. Results of the moderated mediation model revealed that T1 developmental assets could predict less IGD at T2 directly or through $\mathrm{T} 1$ self-control indirectly. Furthermore, the moderating effect of gender was not significant in the mediation model. Overall, adolescents who experience more developmental assets are less likely to suffer IGD. Moreover, developmental assets are conducive to developing a higher level of self-control, which in turn contributes to preventing or intervening in IGD as well. Therefore, measures should be taken to construct developmental assets to prevent or reduce IGD during adolescence.

Keywords: developmental assets, self-control, internet gaming disorder, longitudinal mediation model, adolescent

\section{INTRODUCTION}

During the COVID-19 pandemic, students are participating in online education through various mobile devices, such as computers and mobile phones (1). With these mobile devices, adolescents are more accessible to internet games, which may increase the possibility of internet gaming disorder (IGD). Moreover, the population of adolescents playing internet games is increasing around the world, meaning that more and more adolescents are facing the risk of IGD (2-4). IGD refers to uncontrollable, excessive, and compulsive use of internet games that leads to social and emotional problems (5). It is gradually becoming an important social problem among younger generations and has been included in the International Classification of Diseases (6). Meanwhile, a growing number of studies have demonstrated that IGD can lead to other developmental problems, including mental disorders and problematic behaviors $(3,7)$. More seriously, it will result in a series of alterations in brain function and structure (8-11). Considering the negative consequences 
of IGD, many researchers are devoted to figuring out the mechanisms, causes, and impacts of this phenomenon.

In addition to studying IGD's influence on individuals, researchers have made great achievements in explaining its reasons. Empirical studies have revealed that numerous factors significantly predict IGD, such as depression, anxiety, stress, aggression, peer attachment, social skills, family functioning, and parental monitoring (12-18). However, according to the ecological systems theory, Bronfenbrenner emphasized that different subsystems function as a whole to influence the growth of individuals (19). Thus, the combination of several factors can better explain the causes or mechanisms of IGD. Moreover, it is more in line with reality. Based on this theory, the present study aims to combine some factors to investigate their joint influence on IGD among adolescents. This will not only provide a further understanding of IGD but also contribute to the prevention and intervention of adolescents suffering from IGD among adolescents.

\section{Developmental Assets and IGD}

In recent decades, developmental psychologists, inspired by positive psychology and comparative psychology, have paid increasing attention to positive youth development (PYD). This emerging perspective highlights that all young people have strengths and resources to effectively facilitate their healthy development (20). From this perspective, Benson et al. (21, 22) developed a universally used framework of developmental assets. Developmental assets are defined as 40 important resources that are conducive to positive youth development (23). According to the developmental assets framework (22), these 40 developmental assets can be divided into two categories: social resources (or external assets) and personal resources (internal assets). External assets comprise four kinds of resources, including support (e.g., family and social support, and positive family communication), empowerment (e.g., having responsibilities and chances to serve others and having a sense of safety), boundaries and expectations (e.g., having rules from family, school, and neighborhood and being expected to do well), and constructive use of time (e.g., spending time on creative and social activities). Similarly, internal assets also consist of four kinds of resources, including commitment to learning (e.g., looking forward to academic achievements and positive engagement in school), positive values (e.g., being honest, loyal, and responsible), social competence (e.g., having coping skills and social skills), and positive identity (e.g., self-esteem and having a purpose). These eight kinds of resources cover many assets from different subsystems, including individuals, families, schools, communities, and society. Previous research has confirmed that developmental assets can contribute to the positive growth of youth from various cultures $(22,24-$ 26). Moreover, Chinese youth, with no exception, can also benefit from developmental assets under the perspective of PYD $(27,28)$.

The horizontal stacking assumption of the developmental assets framework stresses that experiencing as many kinds of resources as possible will prevent negative outcomes (22). Based on that, prior studies have indicated the protective function of developmental assets in risky behaviors among various countries' youth $(29,30)$. Encouraged by these findings, the present study aims to evaluate whether developmental assets could reduce or prevent IGD among Chinese youth. Empirical literature has provided evidence supporting the association between developmental assets and IGD indirectly. For instance, Bonnaire and Phan (31) found that family rules (included in boundaries and expectations) can effectively prevent boys from IGD. In a longitudinal study of Chinese adolescents, Su et al. (13) also revealed that parental monitoring (included in boundaries and expectations) plays a vital role in preventing IGD. In the same year, Kim et al. (12) reported that positive father-adolescent communication (included in support) is negatively associated with IGD among Korean adolescents. Similarly, Zhang et al. (32) indicated that social support (included in support) is negatively related to IGD symptoms among Chinese university students. Overall, all these findings from younger generations jointly indicate that IGD might be affected by social resources.

In addition, personal resources have been revealed to have negative impacts on youth IGD as well. Yu and his colleagues' longitudinal study (33) has revealed that the improvement of school engagement (included in commitment to learning) can significantly decrease IGD among adolescents. Moreover, Beard et al. (34) have found that self-esteem (included in positive identity) works as a protective factor to prevent IGD. Similarly, Zhang et al. (32) have indicated that purpose in life (included in positive identity) is an effective factor to protect university students against IGD. Recently, in a longitudinal study of freshmen, Teng et al. (16) have demonstrated that peer attachment (included in social competence) has a bidirectional association with IGD. In summary, both external and internal developmental assets are significantly associated with IGD in different countries' youth, including Chinese adolescents. Therefore, the present study hypothesizes that developmental assets are able to negatively predict adolescent IGD (Hypothesis 1).

\section{Self-Control as a Potential Mediator}

Apart from the direct relationship between developmental assets and IGD, there may be another potential mediating mechanism. Self-control, a possible mediator, is universally considered as an ability to alter undesired behaviors or tendencies (35). High selfcontrol capacity is always associated with positive developmental outcomes, such as successes in learning, relationships, and health $(35,36)$. However, people with low self-control abilities are more likely to face behavioral problems, including criminal problems and substance abuse (37-39). According to the general theory of crime, the most essential reason for crime and other problems is a lack of self-control ability (37). Özdemir et al. (40) and Li et al. (41) reported that low self-control can lead to internet addiction among undergraduate students and adolescents, respectively. Moreover, as a subtype of internet addiction, IGD has a similar association with self-control. Kim et al. (42) found that selfcontrol can negatively predict IGD. Likewise, in a study of university students, poor self-control ability would lead to greater IGD (43). And among Korean adolescents, low self-control can significantly predict IGD (44). Considering the above theory and relevant findings, it is reasonable to believe that self-control ability might have a negative effect on adolescent IGD. That 
is, adolescents with a low self-control capacity may have more possibilities to suffer from IGD.

Gottfredson and Hirschi (37) have stated that self-control ability stays stable over a lifetime. However, more and more research puts forward evidence to the contrary that self-control changes during adolescence $(45,46)$. In addition to genetic effects, self-control ability will be shaped by other factors as well (47). Specifically, previous studies have demonstrated that self-control ability will be affected by developmental resources from different subsystems, such as teacher support, peer support, parental support, positive family communication, good parentchild relationship (included in support), parental supervision and monitoring, school discipline (included in boundaries and expectations) and self-esteem (included in positive identity) (48-53). Additionally, the ecological systems theory points out that subsystems will jointly impact individual development (19), which indicates that other developmental assets not mentioned above might also influence the self-control capacity. Therefore, it is reasonable to think that, as positive factors, developmental assets may also have a positive influence on adolescent selfcontrol ability. Given the complicated association between selfcontrol ability and developmental assets and IGD, the present study hypothesizes that self-control plays a mediating role in the association between developmental assets and IGD among adolescents (Hypothesis 2).

\section{Gender as a Potential Moderator}

Previous evidence has shown that there are gender differences in developmental assets, self-control, and IGD. In a study of Indian youth, significant gender differences were found in both internal and external developmental assets (54). Similarly, Portuguese boys and girls experienced different developmental assets (55).
A recent finding by Gomez-Baya et al. (56) reported that Spanish adolescents also face the same situation. According to the developmental assets framework (22), experiencing different developmental assets will have different influences on individual growth. Therefore, it is necessary to evaluate the possible gender differences in the present sample. Additionally, Jo and Bouffard (57) revealed that men and women experience similar developmental processes of self-control, but gender differences still exist over the short term. Likewise, Turner et al. (58) and Winfree et al. (59) both reported that women have higher selfcontrol than men. Moreover, several studies have suggested that gender differences appear in IGD as well (60-62). Considering these differences between boys and girls, the present study hypothesizes that gender differences might also exist in the relationship between developmental assets, self-control, and adolescent IGD (Hypothesis 3).

\section{The Present Study}

Although previous studies have made great achievements in the field of IGD, little research has considered this phenomenon from the perspective of PYD. With a combination of the developmental assets framework (22) and the general theory of crime (37) and existing evidence, we further realize the complex association between developmental assets, self-control, and IGD. Accordingly, the present study, based on the PYD, determines to investigate the relationship between developmental assets, selfcontrol, and IGD among Chinese adolescents and constructs a moderated mediation model (see Figure 1). The present study hypothesizes that: (1) developmental assets can negatively predict adolescent IGD; (2) self-control will play a mediating role in the association between developmental assets and IGD among adolescents; and (3) gender differences might exist in

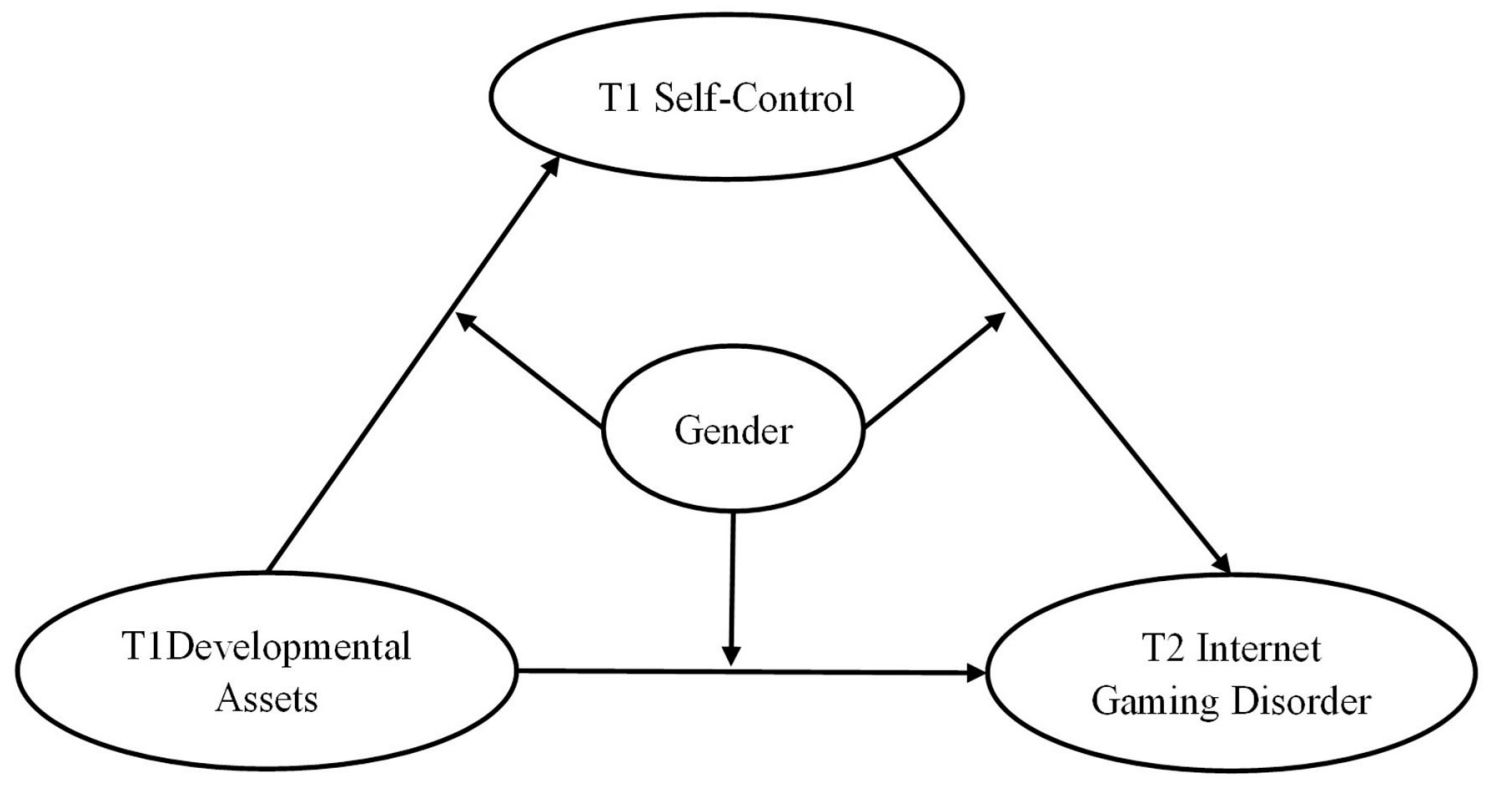

FIGURE 1 | Conceptual moderated mediation model. T1 = Time 1; T2 = Time 2. The same below. 
the relationship between developmental assets, self-control, and adolescent IGD.

\section{METHODS}

\section{Participants and Procedure}

Data was collected from two public middle schools in Southern China. By using a random cluster sampling, a total of 1,023 adolescents from Grade 7 to Grade 9 (505 boys; $\mathrm{M}_{\text {age }}=13.16$ years, $\mathrm{SD}=0.86$ ) were recruited to participate in the longitudinal study and complete the questionnaires. For various reasons, such as transfer, 30 participants dropped out (attrition rate $=$ 2.93\%). Most of the remaining adolescents were from families at the average economic level $(3.10 \%$ were from families under the average economic level and $1.85 \%$ were from families above the average economic level). Moreover, the number of adolescents was about the same in three grades $(35.75 \%$ were in Grade 7, 35.15\% were in Grade 8, and 29.10\% were in Grade 9). Additionally, Table 1 displays several descriptive characteristics of the current sample.

All procedures involving human participants were approved by the Research Ethics Committee of the College of Education and Sports Sciences, Yangtze University. After obtaining verbal consent from the school leaders and students, two researchers with negative test results for COVID-19 administered the questionnaire to participants, taking about half an hour during regular class time. Students were encouraged to self-report honestly by knowing about the anonymity of the questionnaires. The procedures were identical across waves, and the time interval of data collection was 6 months between two waves (Time 1, October 2020). The participation was entirely voluntary, and the students did not receive any compensation for their participation.

\section{Measures}

\section{Developmental Assets at Time 1}

The present study used the Developmental Assets Profile (DAP) to measure adolescents' developmental assets (63). It consists of eight subscales, 58 items in total (e.g., "I have a school that cares about kids and encourages them" in the support subscale). All

TABLE 1 | Descriptive statistics of covariates and key variables.

\begin{tabular}{|c|c|c|c|c|c|c|c|}
\hline & \multicolumn{2}{|c|}{ Boys } & \multicolumn{2}{|c|}{ Girls } & \multicolumn{3}{|c|}{ Total } \\
\hline & $M$ & $S D$ & $M$ & $S D$ & $M$ & $S D$ & Range \\
\hline \multicolumn{8}{|l|}{ COVARIATES } \\
\hline 1. Age & 13.23 & 0.88 & 13.09 & 0.84 & 13.16 & 0.86 & $11-15$ \\
\hline 2. Family type & 2.05 & 1.23 & 2.24 & 1.42 & 2.15 & 1.34 & $1-4$ \\
\hline 3. Family economic status & 1.99 & 0.25 & 1.98 & 0.19 & 1.99 & 0.22 & $1-3$ \\
\hline \multicolumn{8}{|l|}{ KEY VARIABLES } \\
\hline 4. T1 CDAl & 2.60 & 2.42 & 2.486 & 2.35 & 2.54 & 2.38 & $0-8$ \\
\hline 5. T1 SC & 40.13 & 7.03 & 39.82 & 6.96 & 39.97 & 6.99 & $17-63$ \\
\hline 6. T2 IGD & 15.79 & 3.71 & 15.23 & 3.45 & 15.51 & 3.59 & $11-32$ \\
\hline
\end{tabular}

CDAl, Cumulative developmental assets index; SC, Self-control; IGD, Internet gaming disorder. of these items were rated on a four-point scale, ranging from "1 $=$ not at all or rarely" to " $4=$ extremely or almost always." The composite of developmental assets came from the total scores of all subscales. This questionnaire demonstrated good reliability and validity among Chinese adolescents (64). In the present study, the Cronbach's alpha at time 1 was 0.95 .

Inspired by previous literature $(29,64)$, the present study decided to construct the cumulative developmental assets index (CDAI) to reflect the breadth of developmental resources. Based on the average item response, this study chose " 3 very or often" (indicating that students have many developmental assets) as the dividing point and binary recoded the eight subscales. More than or equal to the number of items in the subscale multiplied by three. The code of subscale scores was one to indicate that adolescents have this kind of developmental asset; otherwise, the code was zero to show that they do not have this kind of developmental asset. Then, add the scores recoded in each subscale to obtain the cumulative developmental assets index.

\section{Self-Control at Time 1}

The present study used the 13-item Brief Self-Control Scale (BSCS) (35) to assess adolescents' self-control (e.g., "Pleasure and fun sometimes keep me from getting work done"). And all of them were rated on a five-point scale (from " $1=$ not like me at all" to " $5=$ very much like me"). The composite score of BSCS came from the total scores of all items, with a higher score indicating better self-control ability. Among Chinese adolescents, this scale has good reliability and validity (65). Its Cronbach's alpha at time 1 was 0.71 in the present study.

\section{Internet Gaming Disorder at Time 2}

The present study used the 11-item Internet Gaming Disorder Questionnaire (IGDQ) (66) to measure adolescents' IGD (e.g., "Do you sometimes skip doing homework in order to spend more time playing online games?"). All items were rated on a 3point scale, ranging from " $1=$ never" to " $3=$ frequently." The composite of IGDQ came from the average scores of all items, with higher scores indicating higher levels of IGD. In Chinese adolescents, this questionnaire has good reliability and validity (66). Its Cronbach's alpha at time 2 was 0.77 in the present study.

\section{Demographics}

At both waves, the present study also collected several demographic variables, including adolescent age, gender $(1=$ boys, $2=$ girls $)$, grade, family type $(1=$ parents with one kid, 2 $=$ parents with more than one kid, $3=$ single-parent family with one kid, 4 = single-parent family with more than one kid), and family economic status ( $1=$ under the average level, $2=$ equal to the average level, $3=$ above the average level).

\section{Data Analysis}

Initially, the present study conducted the attrition analysis and common method bias analyses with SPSS 26.0. Second, descriptive statistics and correlations of the key variables were also calculated to assess the hypotheses 1. Third, structural equation modeling (SEM) and multigroup analysis were used to test the mediation model and the moderated mediation model 
in Mplus 8.0 (67). To examine the hypotheses 2, a mediation model was constructed to assess the mediating effect of T1 selfcontrol between T1 developmental assets and T2 IGD. Then, multigroup analysis was performed to test the hypotheses 3 , the possible moderating effect of gender on the mediation model. Several model fit indices were evaluated in the present study, such as the values of Chi-square, degree of freedom, root mean square error of approximation (RMSEA; acceptable $<0.08$, good $<0.05$ ), comparative fit index (CFI; acceptable $>0.90$, good $>0.95$ ), Tucker-Lewis Index (TLI; acceptable $>0.90$, good $>$ 0.95 ) and the standardized root mean square residual (SRMR; acceptable $<0.08$, good $<0.05)(68)$. Across the models in the present study, missing data was handled with full information maximum likelihood estimation (FIML) (69).

\section{RESULTS}

\section{Attrition Analysis and Common Method Biases Analyses}

Prior to any further analysis, Chi-square tests and $t$-tests were conducted in SPSS 26, in order to examine the potential bias between participants who dropped out at time 2 and those who had provided data across two time points. The results showed that these two groups did not differ in T1 developmental assets $\left[t_{(28)}\right.$ $=0.96, p=0.346]$, T1 self-control $\left[t_{(29)}=1.06, p=0.299\right]$, T2 $\operatorname{IGD}\left[t_{(1,017)}=-0.83, p=0.409\right]$, gender $\left[\chi_{(1)}^{2}=1.08, p=0.298\right]$, family type $\left[\chi_{(5)}^{2}=5.02, p=0.413\right]$, and family economic $\left[\chi_{(2)}^{2}\right.$ $=0.56, p=0.756]$, revealing that the data set would not be biased due to attrition.

Second, to control the possible common method variance, the present study employed questionnaires with revering items and various types of scales response options (70). Besides, Harman's Single-Factor Test was also performed to test it (71). The results reported 25 factors with eigenvalues greater than one, and the first factor accounted for $16.19 \%$ of total variance, indicating that all results in the present study were less influenced by common method biases.

\section{Descriptive Statistics and Correlation Analyses}

Table 2 outlines skewness, kurtosis, and intercorrelations of all variables. Specifically, T1 self-control was positively associated with T1 CDAI $(r=0.28,95 \% \mathrm{CI}=[0.219,0.335])$ and family economy $(r=0.10,95 \% \mathrm{CI}=[0.036,0.164])$, while it was negatively connected with T2 IGD $(r=-0.19,95 \%$ $\mathrm{CI}=[-0.256,-0.123])$, and family type $(r=-0.11,95 \%$ $\mathrm{CI}=[-0.161,-0.043])$. Additionally, T2 IGD was negatively associated with T1 CDAI $(r=-0.11,95 \% \mathrm{CI}=[-0.172$, $-0.054])$, family economy $(r=-0.11,95 \% \mathrm{CI}=[-0.191$, $-0.017])$, and gender $(r=-0.08,95 \% \mathrm{CI}=[-0.136,-0.013])$.

\section{The Mediation Effect of T1 Self-Control}

A mediation model was constructed to test whether T1 selfcontrol mediates the pathway from T1 CDAI to T2 IGD. And the results suggested that this model fit the data very well: $\chi_{(d f)}^{2}$ $=70.37(33)$, RMSEA $=0.04(95 \% \mathrm{CI}=[0.026,0.053]), \mathrm{CFI}$
TABLE 2 | Skewness, kurtosis, and intercorrelations of covariates and key variables.

\begin{tabular}{lrrrrrrr}
\hline & Skewness & Kurtosis & $\mathbf{1}$ & $\mathbf{2}$ & $\mathbf{3}$ & $\mathbf{4}$ & $\mathbf{5}$ \\
\hline COVARIATES & & & & & & & \\
1. Gender & -0.01 & -2.00 & & & & \\
2. Family type & 1.10 & 0.51 & $0.07^{*}$ & & & \\
3. Family & -1.02 & 17.12 & -0.01 & -0.01 & &
\end{tabular}

economic

status

\section{KEY VARIABLES}

4. T1 CDAl $\quad 0.67 \quad-0.67 \quad-0.02 \quad-0.05 \quad 0.05$

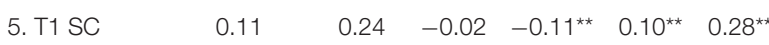

6. T2 IGD $\quad 1.71 \quad 3.68 \quad-0.08^{\star} \quad 0.04-0.10^{\star \star}-0.11^{\star \star}-0.19^{* \star}$

CDAl, Cumulative developmental assets index; SC, Self-control; IGD, Internet gaming disorder. ${ }^{*} p<0.05,{ }^{* *} p<0.01$.

$=0.987$, TLI $=0.981$ and SRMR $=0.029$. Furthermore, as illustrated in Figure 2, T1 CDAI could negatively predict the T2 IGD $(\beta=-0.15, p=0.005)$ and it could also predict T2 IGD through T1 self-control indirectly. Specifically, T1 CDAI positively influenced T1 self-control $(\beta=0.23, p=0.001)$, which had a negative effect on T2 IGD $(\beta=-0.13, p=0.005)$. These results confirmed the mediation role of T1 self-control between T1 CDAI and T2 IGD $(\beta=-0.03,95 \% \mathrm{CI}=[-0.066,-0.007])$. That is, hypothesis 1 and hypothesis 2 were both confirmed.

\section{The Moderation Effect of Gender}

Multigroup analysis was used to assess the possible moderation effect of gender on the mediation model. Based on the mediation model mentioned above, the present study added gender as a grouping item, and the new model also fit the data well: $\chi_{(d f)}^{2}$ $=144.80$ (60), RMSEA $=0.06$ (95\% CI $=[0.045,0.069])$, CFI $=0.967$, TLI $=0.960$ and SRMR $=0.049$. Then, Wald-Test was conducted to examine the possible gender differences in the mediation model. The results did not support the assumption of Wald-Test $\left(\chi^{2}=1.011, p=0.315\right)$, suggesting that there was no significant gender difference in the mediation model. Thus, hypothesis 3 was not supported.

\section{DISCUSSION}

To investigate the relationship between developmental assets, self-control, and IGD during adolescence, the present study adopts a two-wave longitudinal design and proposes a moderated mediation model. And the results generally confirm the hypothesized model. The major finding is that self-control mediates the association between developmental assets and IGD, which provides a new and comprehensive perspective for a deeper understanding of IGD among adolescents. Moreover, this finding indicates that various measures from different subsystems should be taken to prevent or intervene with adolescents suffering from IGD. The following paragraphs explain all the findings in detail. 


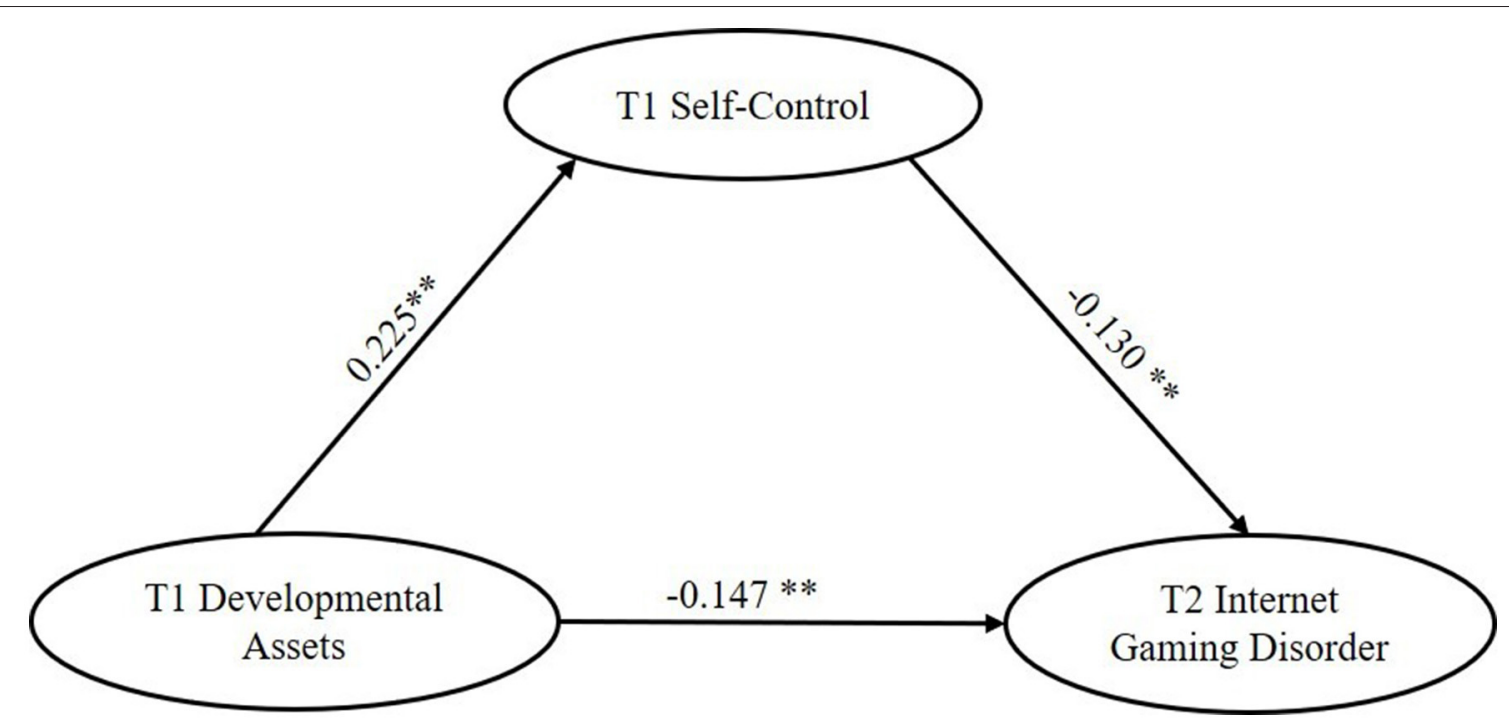

FIGURE 2 | The mediating effect of T1 self-control in the relationship between T1 developmental assets and T2 internet gaming disorder. Standardized coefficients are reported; ${ }^{\star *} p<0.01$.

\section{Developmental Assets and IGD}

Previous studies have revealed that some specific contents of developmental resources are associated with IGD, such as social support, family rules, and school engagement (13, 31-33). Inspired by that indirect evidence, the present study aims to figure out whether they have a direct association. As expected, a significant relationship between developmental assets and IGD was disclosed directly through the longitudinal design. Specifically, developmental assets could negatively predict IGD half a year later. That is, experiencing as many developmental assets as possible could effectively reduce the risk of suffering IGD. Developmental assets play a protective role in IGD, which is in line with previous empirical evidence. For instance, Chang et al. (64) have found that developmental assets have cumulative effects on reducing externalizing behaviors among adolescents. Likewise, Mazloomi et al. (72) have also demonstrated that developmental assets could reduce addiction potential effectively. Overall, developmental assets serve as protective factors to prevent adolescents from having negative developmental outcomes.

Additionally, this finding also provides empirical support for the horizontal stacking assumption of the developmental assets framework (22). It stresses that experiencing as many kinds of resources as possible can prevent or reduce negative outcomes. In the present study, the CDAI was adopted to assess the cumulative effect of eight kinds of developmental assets on IGD. And results have suggested that the more developmental assets adolescents experience, the less likely they will be addicted to internet games. One possible explanation is the multiple protective functions $(22,64)$. Every kind of developmental resource is a protective layer that has its own unique effect and contributes to individual growth. The more developmental assets adolescents have, the more layers will protect their growth. The joint protective layers of developmental assets can form a giant umbrella, which in turn will stop adolescents from developmental problems and escort their healthy development. From the perspective of the developmental assets framework, constructing enough developmental resources is essential for the prevention and intervention of IGD and other negative outcomes.

\section{Mediating Role of Self-Control}

Consistent with the second hypothesis, developmental assets could also decrease IGD indirectly through improving selfcontrol. This finding provides longitudinal evidence for the ecological systems theory (19), which suggests that subsystems will jointly impact individual development. In the present study, developmental assets and self-control come from different subsystems such as individuals, families, schools, communities, and society. The significant influence of 40 resources and selfcontrol on IGD supports the theory to a certain degree. Moreover, the present finding also corroborates the notion of the general theory of crime that lack of self-control ability is a critical reason for suffering IGD (37). Therefore, enhancing this ability could effectively decrease the prevalence of IGD among adolescents. Additionally, this finding is consistent with previous studies on the negative association between self-control and IGD $(42,44)$, but it also extends them by providing an actionable approach to improve the capability.

This finding can be more deeply understood with the combination of two theories. According to the developmental assets framework (22), developmental assets can promote positive developmental results (e.g., high self-control). Thus, experiencing as many developmental assets as possible is beneficial for the improvement of self-control. This is repeatedly confirmed by empirical studies (48-50). In addition, as highlighted in the general theory of crime (37), self-control 
is a vital capacity, the lack of which is the most essential reason for crime and other problems. In other words, improving self-control can effectively avoid or prevent crime and many problems, including IGD. Moreover, experiencing developmental assets is an effective and convenient way to increase the level of self-control ability. To sum up, developmental assets are helpful in developing a higher level of self-control, which in turn will prevent adolescents from suffering IGD. This finding deepens the understanding of the mechanism of the relationship between developmental assets and IGD. Therefore, various measures should be taken to provide as many developmental resources as possible in order to improve self-control ability.

\section{Moderating Role of Gender}

Abundant empirical evidence has suggested gender differences in developmental assets, self-control, and IGD (55-57, 60-62). However, inconsistent with the literature, gender could not significantly moderate the mediation model in the present study. One possible explanation can be given for the insignificant moderating effect of gender. In the present study, CDAI was adopted as an indicator of developmental assets, which is a binary coded variable. And it may result in the loss of other important information about gender difference in the developmental assets. Soares et al.'s study (55) confirmed that gender differences were significant in the continuous distributions of developmental assets, while they were insignificant in the binary recoded index. Therefore, the binary recoding method might be an important reason. Future studies should cautiously adopt the binary recoding method and are encouraged to evaluate the gender difference with unrecorded scores of variables, which can reflect the situation more adequately.

\section{Limitations and Implications}

It is necessary to consider several limitations of the present studies. First, the data was collected through self-reported questionnaires, which might include unreal answers and cannot avoid being influenced by shared method bias. So, multiple measures should be combined to investigate the relationship, for example, peer-reported questionnaires. Second, the present study only assessed the impacts of 40 developmental assets and one personality variable on IGD. However, developmental assets might include more factors. Future research could combine other factors to investigate their relationships with IGD. Third, although the present study adopted a longitudinal design, the time span is only half a year, which is too short in lifetime. Future research could adopt a longer longitudinal study. Last but not least, the present study only focused on Chinese adolescents. The findings might not be suitable for young people from other cultures. Therefore, in order to obtain more generalizable findings, future studies are encouraged to concentrate more on cross-cultural samples.

In terms of application, the present study has several implications. First, the present findings suggest that more attention should be paid to the positive factors (e.g., developmental assets) in adolescent growth. Second, comprehensive measures should be taken to construct development resources for adolescents to address the developmental challenges. For instance, parents can give more material and psychological support, communicate in a positive way, and build good relationships with adolescents. Their community and school can give them more opportunities to serve others and take on responsibilities. Third, self-control is an important ability that develops during the first decade and works through the lifetime to protect individuals. Therefore, parents have to consciously spare no effect to assist their children to develop this capability in the first decade of their lifetime.

\section{CONCLUSION}

From the perspective of positive youth development, scholars indicate that developmental assets play a critical role in promoting adolescent development. The present study examined how their joint function affected the development of Chinese adolescents during the COVID-19 pandemic. Specifically, the present study explored the relationship between developmental assets, self-control, and IGD through a moderated mediation model based on a longitudinal study. Adolescents who have more developmental assets are less likely to develop IGD. Moreover, the cumulative developmental assets are beneficial to a higher level of self-control ability, which in turn contributes to preventing or decreasing IGD. In summary, measures should be taken to construct developmental assets to assist adolescents in responding to the developmental challenges during adolescence.

\section{DATA AVAILABILITY STATEMENT}

The raw data supporting the conclusions of this article will be made available by the authors, without undue reservation.

\section{ETHICS STATEMENT}

The studies involving human participants were reviewed and approved by the Research Ethics Committee of College of Education and Sports Sciences, Yangtze University. Written informed consent to participate in this study was provided by the participants' legal guardian/next of kin.

\section{AUTHOR CONTRIBUTIONS}

XG designed the work. G-XX and Y-HZ collected the data. G$\mathrm{XX}$ analyzed the data and drafted the manuscript. XG, G-XX, XJ, and C-SZ revised the manuscript. All authors contributed to the article and approved the submitted version.

\section{FUNDING}

This research was supported by Youth Project of Natural Science Foundation of Hubei Province in 2020 (2020CFB365) and Achievements of key projects of education science plan of Hubei Province in 2019 (2019GA017). 


\section{REFERENCES}

1. Zhu X, Liu J. Education in and after Covid-19: immediate responses and long-term visions. Postdigital Sci Educ. (2020) 2:695-9. doi: 10.1007/s42438-020-00126-3

2. China Internet Network Information Center (2021). The 47th Statistic Report of China Internet Network Development State. Available online at: http://www. cnnic.net.cn/hlwfzyj/hlwxzbg/hlwtjbg/202102/P020210203334633480104.pdf

3. Mihara S, Higuchi S. Cross-sectional and longitudinal epidemiological studies of Internet gaming disorder: a systematic review of the literature. Psychiatry Clin Neurosci. (2017) 71:425-44. doi: 10.1111/pcn.12532

4. Fam JY. Prevalence of internet gaming disorder in adolescents: a meta-analysis across three decades. Scand J Psychol. (2018) 59:52431. doi: 10.1111/sjop.12459

5. Young KS, De Abreu CN. Internet Addiction. A Handbook and Guide to Evaluation. Hoboken: John Wiley \& Sons Inc (2011).

6. World Health Organization. The 11th International Classification of Diseases (ICD-11). (2018). Available online at: https://icd.who.int/browse11/1-m/en

7. Kim YJ, Lim JA, Lee JY, Oh S, Kim SN, Kim DJ, et al. Impulsivity and compulsivity in Internet gaming disorder: a comparison with obsessivecompulsive disorder and alcohol use disorder. J Behav Addict. (2017) 6:54553. doi: 10.1556/2006.6.2017.069

8. Tian M, Chen Q, Zhang Y, Du F, Hou H, Chao F, et al. PET imaging reveals brain functional changes in internet gaming disorder. Eur J Nucl $\mathrm{Med} \mathrm{Mol}$ Imaging. (2014) 41:1388-97. doi: 10.1007/s00259-014-2708-8

9. Liu J, Li W, Zhou S, Zhang L, Wang Z, Zhang Y, et al. Functional characteristics of the brain in college students with internet gaming disorder. Brain Imaging Behav. (2016) 10:60-7. doi: 10.1007/s11682-015-9364-x

10. Wang L, Wu L, Lin X, Zhang Y, Zhou H, Du X, et al. Altered brain functional networks in people with Internet gaming disorder: evidence from resting-state fMRI. Psychiatry Res Neuroimaging. (2016) 254:15663. doi: 10.1016/j.pscychresns.2016.07.001

11. Weinstein AM. An update overview on brain imaging studies of internet gaming disorder. Front Psychiatry. (2017) 8:185. doi: 10.3389/fpsyt.2017.00185

12. Kim E, Yim HW, Jeong H, Jo SJ, Lee HK, Son HJ, et al. The association between aggression and risk of Internet gaming disorder in Korean adolescents: the mediation effect of father-adolescent communication style. Epidemiol Health. (2018) 40:1-7. doi: 10.4178/epih.e2018039

13. Su B, Yu C, Zhang W, Su Q, Zhu J, Jiang Y. Father-child longitudinal relationship: parental monitoring and Internet gaming disorder in Chinese adolescents. Front Psychol. (2018) 9:95. doi: 10.3389/fpsyg.2018.00095

14. Bonnaire C, Baptista D. Internet gaming disorder in male and female young adults: the role of alexithymia, depression, anxiety and gaming type. Psychiatry Res. (2019) 272:521-30. doi: 10.1016/j.psychres.2018.12.158

15. Andreetta J, Teh MSc J, Burleigh TL, Gomez R, Stavropoulos V. Associations between comorbid stress and Internet Gaming Disorder symptoms: are there cultural and gender variations? Asia Pacific Psychiatry. (2020) 12: e12387. doi: 10.1111/appy.12387

16. Teng Z, Griffiths MD, Nie Q, Xiang G, Guo C. Parent-adolescent attachment and peer attachment associated with Internet Gaming Disorder: a longitudinal study of first-year undergraduate students. J Behav Addict. (2020) 9:11628. doi: 10.1556/2006.2020.00011

17. Fumero A, Marrero RJ, Bethencourt JM, Peñate W. Risk factors of internet gaming disorder symptoms in Spanish adolescents. Comput Human Behav. (2020) 111:106416. doi: 10.1016/j.chb.2020.106416

18. Yuan G, Elhai JD, Hall BJ. The influence of depressive symptoms and fear of missing out on severity of problematic smartphone use and Internet gaming disorder among Chinese young adults: a three-wave mediation model. Addict Behav. (2021) 112:106648. doi: 10.1016/j.addbeh.2020.106648

19. Bronfenbrenner U, Morris PA. The ecology of developmental processes. Handbook Child Psychol. (1998) 1:993-1028.

20. Lerner RM. The positive youth development perspective: theoretical and empirical bases of strengths-based approach to adolescent development. Oxford Handbook Positive Psychol. (2009) 149:163. doi: 10.1093/oxfordhb/9780195187243.013.0014

21. Leffert N, Benson PL, Scales PC, Sharma AR, Drake DR, Blyth DA. Developmental assets: Measurement and prediction of risk behaviors among adolescents. Appl Dev Sci. (1998) 2:209-30. doi: 10.1207/s1532480xads0204_4
22. Benson PL, Scales PC, Syvertsen AK. The contribution of the developmental assets framework to positive youth development theory and practice. Adv Child Dev Behav. (2011) 41:197230. doi: 10.1016/B978-0-12-386492-5.00008-7

23. Benson PL. Developmental assets: an overview of theory, research, and practice. Approaches Positive Youth Dev. (2007) 33:58. doi: 10.4135/9781446213803.n2

24. Scales PC, Benson PL, Leffert N, Blyth DA. Contribution of developmental assets to the prediction of thriving among adolescents. Appl Dev Sci. (2000) 4:27-46. doi: 10.1207/S1532480XADS0401_3

25. Edwards OW, Mumford VE, Shillingford MA, Serra-Roldan R. Developmental assets: a prevention framework for students considered at risk. Child Sch. (2007) 29:145-53. doi: 10.1093/cs/29.3.145

26. Bleck J, DeBate R. Long-term association between developmental assets and health behaviors: an exploratory study. Health Educ Behav. (2016) 43:54351. doi: $10.1177 / 1090198115606915$

27. Chen B-B, Li X, Chen N. Positive youth development in China. In: Dimitrova $\mathrm{R}$, editor. Well-Being of Youth and Emerging Adults Across Cultures: Novel Approaches and Findings From Europe, Asia, Africa and America. New York: Springer (2016). p. 35-49.

28. Chen B-B, Wiium N, Dimitrova R. A life history approach to understanding developmental assets among Chinese adolescents. Child Youth Care Forum. (2017) 48:155-69. doi: 10.1007/s10566-017-9433-y

29. Manrique-Millones D, Wiium N, Pineda-Marín C, Fernández-Arata M, Alfonso-Murcia D, López-Martínez JL, et al. Association between substance use behaviors, developmental assets and mental health: a glance at Latin American Young College Students. Front Psychol. (2021) 12:489. doi: 10.3389/fpsyg.2021.639578

30. Pivec T, Kozina A, Wiium N, Uka F. Are the 5Cs of positive youth development related to risky behaviors? Analysis across countries. In: Pracana C, Wang M, editors. Psychology Applications \& Developments VI. Lisboa: InScience Press (2021). p. 194-203.

31. Bonnaire C, Phan O. Relationships between parental attitudes, family functioning and Internet gaming disorder in adolescents attending school. Psychiatry Res. (2017) 255:104-10. doi: 10.1016/j.psychres.2017.05.030

32. Zhang MX, Wang X, Shu MY, Wu AM. Purpose in life, social support, and internet gaming disorder among Chinese university students: a 1-year followup study. Addict Behav. (2019) 99:106070. doi: 10.1016/j.addbeh.2019.106070

33. Yu C, Li X, Zhang W. Predicting adolescent problematic online game use from teacher autonomy support, basic psychological needs satisfaction, and school engagement: A 2-year longitudinal study. Cyberpsychol Behav Soc Netw. (2015) 18:228-33. doi: 10.1089/cyber.2014.0385

34. Beard CL, Haas AL, Wickham RE, Stavropoulos V. Age of initiation and internet gaming disorder: the role of self-esteem. Cyberpsychol Behav Soc Netw. (2017) 20:397-401. doi: 10.1089/cyber.2017.0011

35. Tangney JP, Baumeister RF, Boone AL. High self-control predicts good adjustment, less pathology, better grades, and interpersonal success. J Pers. (2004) 72:271-324. doi: 10.1111/j.0022-3506.2004.00263.x

36. Boals A, Vandellen MR, Banks JB. The relationship between self-control and health: The mediating effect of avoidant coping. Psychol Health. (2011) 26:1049-62. doi: 10.1080/08870446.2010.529139

37. Gottfredson MR, Hirschi T. A General Theory of Crime. Stanford University Press (1990). Available online at: https://psycnet.apa.org/record/1990-97753000

38. Wills TA, Stoolmiller M. The role of self-control in early escalation of substance use: a time-varying analysis. J Consult Clin Psychol. (2002) 70:986. doi: 10.1037/0022-006X.70.4.986

39. Desmond SA, Ulmer JT, Bader CD. Religion, self-control, and substance use Deviant Behav. (2013) 34:384-406. doi: 10.1080/01639625.2012.726170

40. Özdemir Y, Kuzucu Y, Ak S. Depression loneliness and Internet addiction: how important is low self-control? Comput Human Behav. (2014) 34:28490. doi: 10.1016/j.chb.2014.02.009

41. Li C, Dang J, Zhang X, Zhang Q, Guo J. Internet addiction among Chinese adolescents: The effect of parental behavior and self-control. Comput Human Behav. (2014) 41:1-7. doi: 10.1016/j.chb.2014.09.001

42. Kim EJ, Namkoong K, Ku T, Kim SJ. The relationship between online game addiction and aggression, self-control and narcissistic personality traits. Euro Psychiatry. (2008) 23:212-8. doi: 10.1016/j.eurpsy.2007.10.010 
43. Mills DJ, Allen JJ. Self-determination theory, internet gaming disorder, and the mediating role of self-control. Comput Human Behav. (2020) 105:106209. doi: 10.1016/j.chb.2019.106209

44. Jeong H, Yim HW, Lee SY, Lee HK, Potenza MN, Jo SJ, et al. Low self-control and aggression exert serial mediation between inattention/hyperactivity problems and severity of internet gaming disorder features longitudinally among adolescents. J Behav Addict. (2020) 9:401-9. doi: 10.1556/2006.2020.00039

45. Meldrum RC, Young JT, Weerman FM. Changes in self-control during adolescence: investigating the influence of the adolescent peer network. J Crim Justice. (2012) 40:452-62. doi: 10.1016/j.jcrimjus.2012.07.002

46. Zondervan-Zwijnenburg MAJ, Richards JS, Kevenaar ST, Becht AI, Hoijtink HJA, Oldehinkel AJ, et al. Robust longitudinal multi-cohort results: the development of self-control during adolescence. Dev Cogn Neurosci. (2020) 45:100817. doi: 10.1016/j.dcn.2020.100817

47. Willems YE, Boesen N, Li J, Finkenauer C, Bartels M. The heritability of self-control: a meta-analysis. Neurosci Biobehav Rev. (2019) 100:32434. doi: 10.1016/j.neubiorev.2019.02.012

48. Zhang R, Qiu Z, Li Y, Liu L, Zhi S. Teacher support, peer support, and externalizing problems among left-behind children in rural China: sequential mediation by self-esteem and self-control. Child Youth Serv Rev. (2021) 121:105824. doi: 10.1016/j.childyouth.2020.105824

49. Wills TA, Gibbons FX, Gerrard M, Murry VM, Brody GH. Family communication and religiosity related to substance use and sexual behavior in early adolescence: a test for pathways through selfcontrol and prototype perceptions. Psychol Addict Behav. (2003) 17:312. doi: 10.1037/0893-164X.17.4.312

50. Cho IY, Kim JS, Kim JO. Factors influencing adolescents' self-control according to family structure. J Child Fam Stud. (2018) 27:352030. doi: 10.1007/s10826-018-1175-4

51. Hope TL, Grasmick HG, Pointon LJ. The family in Gottfredson and Hirschi's general theory of crime: structure, parenting, and self-control. Sociol Focus. (2003) 36:291-311. doi: 10.1080/00380237.2003.10571226

52. Li JB, Willems YE, Stok FM, Deković M, Bartels M, Finkenauer C. Parenting and self-control across early to late adolescence: a three-level meta-analysis. Perspect Psychol Sci. (2019) 14:967-1005. doi: 10.1177/1745691619863046

53. $\mathrm{Li}$ JB, Bi SS, Willems YE, Finkenauer C. The association between school discipline and self-control from preschoolers to high school students: a three-level meta-analysis. Rev Educ Res. (2021) 91:73-111. doi: 10.3102/0034654320979160

54. Satheesan S, Hameed N. Gender differences in developmental assets profile of college going youth: a report from India. Int J Commun Med Public Health. (2018) 5:714-20. doi: 10.18203/2394-6040.ijcmph20180256

55. Soares AS, Pais-Ribeiro JL, Silva I. Developmental assets predictors of life satisfaction in adolescents. Front Psychol. (2019) 10:236. doi: 10.3389/fpsyg.2019.00236

56. Gomez-Baya D, Santos T, Gaspar de Matos M. Developmental assets and positive youth development: an examination of gender differences in Spain. Appl Dev Sci. (2021) 1-23. doi: 10.1080/10888691.2021.1906676

57. Jo Y, Bouffard L. Stability of self-control and gender. J Crim Justice. (2014) 42:356-65. doi: 10.1016/j.jcrimjus.2014.05.001

58. Turner MG, Piquero AR. The stability of self-control. J Crim Justice. (2002) 30:457-71. doi: 10.1016/S0047-2352(02)00169-1

59. Winfree Jr LT, Taylor TJ, He N, Esbensen FA. Self-control and variability over time: Multivariate results using a 5-year, multisite panel of youths. Crime Delinquency. (2006) 52:253-86. doi: 10.1177/0011128705278012

60. Ko CH, Yen JY, Chen CC, Chen SH, Yen CF. Gender differences and related factors affecting online gaming addiction among Taiwanese adolescents. J Nerv Ment Dis. (2005) 193:273-7. doi: 10.1097/01.nmd.0000158373. 85150.57
61. Su W, Han X, Yu H, Wu Y, Potenza MN. Do men become addicted to internet gaming and women to social media? A meta-analysis examining genderrelated differences in specific internet addiction. Comput Human Behav. (2020) 113:106480. doi: 10.1016/j.chb.2020.106480

62. Buono FD, Paul E, Sprong ME, Smith EC, Garakani A, Griffiths MD. Gaming and gaming disorder: a mediation model gender, salience, age of gaming onset, and time spent gaming. Cyberpsychol Behav Soc Netw. (2020) 23:64751. doi: 10.1089/cyber.2019.0445

63. Scales PC. Youth developmental assets in global perspective: results from international adaptations of the developmental assets profile. Child Indic Res. (2011) 4:619-45. doi: 10.1007/s12187-011-9112-8

64. Chang S, Zhang L, Wang L. The cumulative effects and relationship model of developmental assets used to reduce adolescent externalizing behaviors. Acta Psychol Sin. (2019) 51:1244-55. doi: 10.3724/SP.J.1041.2019.01244

65. Gu M. A longitudinal study of daily hassles, internet expectancy, self-control, and problematic internet use in Chinese adolescents: a moderated mediation model. Pers Individ Dif. (2020) 152:109571. doi: 10.1016/j.paid.2019.109571

66. Yu C, Tang C, Lin Z, Zhang Q. The interplay between multilevel individual and environmental factors acting on the internet gaming disorder in adolescents: based on the latent profile analysis. Educ Measure Evaluat. (2017) 10:33-44. doi: 10.16518/j.cnki.emae.2017.06.006

67. Muthén LK, Muthén BO. Mplus Version 7 User's Guide. Los Angeles, CA: Muthén \& Muthén (2012).

68. Yu CY. Evaluating Cutoff Criteria of Model Fit Indices for Latent Variable Models With Binary and Continuous Outcomes. Los Angeles: University of California, Los Angeles (2002).

69. Enders CK, Bandalos DL. The relative performance of full information maximum likelihood estimation for missing data in structural equation models. Struct Equ Model. (2001) 8:43057. doi: 10.1207/S15328007SEM0803_5

70. Rodríguez-Ardura I, Meseguer-Artola A. How to prevent, detect and control common method variance in electronic commerce research. $J$ Theor Appl Electronic Commerce. (2020) 15:1-5. doi: 10.4067/S0718-187620200002 00101

71. Aguirre-Urreta MI, Hu J. Detecting common method bias: performance of the Harman's single-factor test. ACM SIGMIS Database. (2019) 50:4570. doi: 10.1145/3330472.3330477

72. Mazloomi A, Davoudi H, Heidari H, Asgari M. Relationship between developmental assets and addiction potential with regard to mediating role of alexithymia in adolescents of Arak, Iran. Int Arch Health Sci. (2019) 6:93. doi: 10.4103/iahs.iahs_55_18

Conflict of Interest: The authors declare that the research was conducted in the absence of any commercial or financial relationships that could be construed as a potential conflict of interest.

Publisher's Note: All claims expressed in this article are solely those of the authors and do not necessarily represent those of their affiliated organizations, or those of the publisher, the editors and the reviewers. Any product that may be evaluated in this article, or claim that may be made by its manufacturer, is not guaranteed or endorsed by the publisher.

Copyright (C) 2022 Xiang, Gan, Jin, Zhang and Zhu. This is an open-access article distributed under the terms of the Creative Commons Attribution License (CC BY). The use, distribution or reproduction in other forums is permitted, provided the original author(s) and the copyright owner(s) are credited and that the original publication in this journal is cited, in accordance with accepted academic practice. No use, distribution or reproduction is permitted which does not comply with these terms. 